\title{
Security Cooperation and Change of Identities in Central Asia: A Model of Acculturation through Security Regionalization in the Shanghai Cooperation Organization
}

\author{
ASKHAT SAFIUllin $^{*}$ AND BRENDAN M. Howe ${ }^{* *}$
}

Since its establishment in 2001, The Shanghai Cooperation Organization (SCO) has gradually increased its influence and importance while becoming an independent venue for the Central Asian states to manage regional and national security. The SCO focuses on a new type of (non-traditional) security, and its diverse membership differentiates it from other security institutions. In particular, and uniquely, the SCO has impacted the national security identities of its members. The processes examined in this paper are not easily reconciled with traditional state-centric security paradigms or the dominant strategic discourse. Thus, recourse must be had to analytical tools provided by social constructivism and, to a lesser extent, English School rationalism. The paper proposes a revised model of socialization with acculturation as a central mechanism and applies it to the security identity formulation of four Central Asian Republics in order to explain the shifts in the security discourses at both the national and regional levels.

Keywords: Regional Security, Shanghai Cooperation

Organization, Security Identity, Acculturation

PhD Candidate, Yonsei Graduate School of International Studies; E-mail: koktube@gmail.com Department Chair, Ewha Graduate School of International Studies; E-mail: bmghowe@yahoo.co.uk 


\section{INTRODUCTION}

C

ontrary to traditional security and strategic approaches, this paper advances strongly the position that internal perceptions and identities are vital for understanding the collective policy output and interaction of groups of states. It also emphasizes that inter-subjective understandings act to constrain and enable state-level actors. In other words security identity formation is a mutually constitutive process between agents (the members) and structure (the Shanghai Cooperation Organization-SCO). Furthermore, it contends that the genealogy of regional security cooperation and identity has left its "civilizing" mark on the actors. Thus this paper argues that the process of security identity and policy formation, particularly with regard to the four states of Central Asia, is best understood through elements of social constructivism and English School rationalism rather than through power political approaches like neorealism or the transformative processes of neoliberalism.

The paper proposes a revised model of socialization with acculturation as a central mechanism and applies it exclusively to the security identity formulation of four Central Asian Republics (Kazakhstan, Kyrgyzstan, Tajikistan, and Uzbekistan, excluding neutral Turkmenistan). Qualitative and quantitative differences in the security relationships between China and Russia, and the four Republics, explain the reasons for the exclusion of the two superpower members of the SCO. First, at the level of interaction, China and Russia prioritize their mutual extra-regional engagement (bilateral relations, participation in the Six-Party Talks and the UN Security Council, and other avenues) over Central Asian regional engagement in the SCO. For Central Asian states, however, it is the region that plays the dominant role in the construction of their foreign policies. Second, the scale of engagement between China and Russia is much higher than engagement with any other Central Asian member. For example, while SCO ministerial-level officials meet and consult on a regular basis with a large number of joint working groups, China and Russia alone have set up thirty-five bilateral groups within this framework (Shambaugh 2004, 74). Therefore, an understanding of the Sino-Russian security hierarchy would require a separate study, which would include multiple external factors. The Central Asian states, sharing similar regional characteristics, are assumed to be influenced more strongly by the processes of the SCO security community.

The starting point for the paper is that ideas matter. They were important in creating images during the Cold War in order to solidify national projects and policies. Ideas remain important in the contemporary international operating environment with regard to creating national identities, which in turn play a role in generating internal solidarity in support of attaining national goals. This is especially true for the Central Asian states, which are recent creations. Inventive elites attempted to generate national identities based on imagined or assumed 
pasts and cultures, but found themselves struggling to forge commonality out of diverse populations that overlapped borders. As artificially created constructs, Central Asian nation-states carry the titular names of ethnic groups (Kazakh, Kyrgyz, Tajik and Uzbek) which are historically unjustified, as they do not fit national borders, do not have historical depth, and, in essence, are a questionable foundation for legitimate and stable states (Weller 2006, 72-74). On the other hand, the collective experiences and interactions of groups of states can themselves impact the identity and perceptions of statesmen. Thus, there is a mutually constitutive process between agents and their local interstate community.

Explanations for the SCO's existence and its purpose vary radically in the IR literature. From one perspective, China saw the redefinition of identities and the creation of new states in the region as a possible security threat, and reacted through engagement. Paralleling its bilateral relations with the states in the region, China introduced a new form of regional multilateral diplomacy in the form of the SCO. The questions of whether it is a counter block to NATO's expansion (Blank 2007; U.S. Congress 2006; Nanay 2007), or whether it has been created to counter the U.S. influence in Central Asia (Ong 2005), have already been vigorously debated. Another argument is that the SCO successfully prevents every member-state from taking any action threatening peace and security in the region (Cornell 2003). In other words, it fulfills the mission of being a collective security mechanism. Recent contrary opinion argues that the SCO strengthens autocracy in the Central Asian republics under the façade of promoting security (Ambrosio 2008). Research on Central Asian security engagement in the SCO is relatively scarce, but what material has been produced is characterized by a clear divide. On one side, the region is presented as being "vulnerable to variable whims of superpower self-interest" (Ros-Lehtinen 2006, 4). On the other, as for instance claimed by Smith (1996), rather than representing a "great game" of the superpowers, inter-state relations resemble a regional power struggle for dominance. The limitations of this bifurcated research agenda have led to a neglect of issues related to identity and norms in regional relations.

The paper is divided into three parts. The first part looks at the theoretical conceptualization of security in Central Asia. The second part examines identity conceptualization by the SCO member-states. It further addresses how these conceptual drivers impact the process of cooperation, and introduces the model of identity change through acculturation. The final part focuses on national approaches to regional cooperation and how these are aggregated to build multilateral cooperation in the SCO.

\section{CONCEPTUALIZING SECURITY AND IDENTITY IN CENTRAL ASIA}

Security regionalization in the Central Asian region has been studied through 
the perspectives of realism (Rashid 2000; Roy 2004, 2008; Bohr 2004; Bhatty 2008; Deyermond 2009) and liberal institutionalism (Aris 2009; Carney and Moran 2000; Sheives 2006). These approaches are limited by their state-centric focus with regard to both the referent object, and their conception of security as achieved by identifying and neutralizing the objective (material) threats faced by the state. Wendtian constructivism, however, adds considerable understanding of the ideas that drive national interests and, potentially, the actions of the members of the SCO (Wendt 1992, 1994, 1995, 1999). For Wendt, to understand interests one should look to identities $(1992,398)$. He also notes the importance of change in the "new understandings of self and other, of acquiring new role identities" $(1992,417)$. The communal norms in the SCO drive cooperation, as it "is through reciprocal interaction that we create and instantiate the relatively enduring social structures in terms of which we define our identities and interests" (Wendt 1992, 406).

Further illumination is provided by the English School of IR. The English School agree with constructivism that anarchy is "what states make of it" (Wendt 1992), and both schools see sovereignty as a phenomenon the meaning of which can be altered by the ideas created by a community of states. But English School authors have placed a primacy on the civilizing effect a society of states can have on its constituent members. Bull $(1977,13)$ posits that a "society of states" is "when a group of states, conscious of certain common interests and common values, form a society in the sense that they conceive themselves to be bound by a common set of rules in their relations with one another, and share in the working of common institutions." According to Bull (1977) the development of these social "rules" naturally emanate from the "fear of unrestricted violence."

Organizations create new internal cultures of interaction between states. A "diplomatic culture" for Bull, is a system of norms and rules that is capable of constraining the violent behavior between states with diverse ambitions and cultures $(1977,316)$. The "international political culture" of the SCO is one that is able to accommodate Central Asian states but does not necessarily replicate the conventions of the European society of states. A more explicit distinction can be made between the role of social norms and culture when contrasted with the national interests of the members in the organization. A group of independent political communities (states) can move beyond merely forming a system, "in the sense that the behavior of each is a necessary factor in the calculations of the others, to establishing, by dialogue and consent common rules and institutions for the conduct of their relations, and by recognizing their common interest in maintaining these arrangements" (Bull and Watson 1984, 1). "Normative" and "institutional" factors create a unique "logic" for that particular international society (Bull and Watson 1984, 9).

In the context of security discourse in Central Asia, Nourzhanov $(2009,96)$ states: 
[T] he official security narrative in Central Asia is quite robust and covers a broad range of issues. It must be noted, however, that: it is heavily influenced by themes, concepts, and terminology coming from abroad (externally induced securitization); its domestic audience is limited; the verbalization of certain threats does not necessarily mean that the regimes perceive them as such; interactions among individual states in the region are almost never securitized. As a result, the discursively produced picture of threats and challenges is skewed, incomplete and does not offer reasonable guidelines for cooperative action.

In order to enhance regional security cooperation, the SCO works by increasing the level of self-restraint. For example, Marketos (2009) finds that the SCO seeks to promote regional confidence and security-building measures (CSBMs) by placing an emphasis on reinforcing transparency and openness in the region. While neoliberal institutionalism's focus on "cooperation" between states would seem applicable to SCO security mechanics, the related prescription of limiting sovereignty for increased cooperation does not fit the model of security regionalism presented in the SCO. The SCO states are more interested in state-building by strengthening their sovereignty. The institution encourages members to adhere to the basic principle of non-intervention and respect for each other's sovereignty. Liberal institutionalism stresses legal norms, rules and material interests, but the SCO states are inclined to retain informal and non-legalistic norm-based rules.

The framework for cooperation in the SCO represents a mixture of formal and informal (non-legalistic) methods termed the "Shanghai Spirit," within which members are not necessarily pushing the organization towards a legally-binding security architecture. From the English School perspective, however, a complex of identities (ethnic, ideological and group identities) forms a set of drivers that have diverse (incremental or detrimental) effects on the process of integration (Jackson 1992, 271). According to Bohr (2004, 502) regional identity "will remain a chimera, and regionalization in the narrowly-defined Central Asian region is unlikely to move." Central Asian states are splintered across ethnic, linguistic and national identities thus, the regional "collective identity" has been conceived to frame the SCO as a process through which its member states have the chance to come together. It is in China's interests to arrest the regional tendency to disintegration and proliferation of ideologically suspect entities; hence, Beijing's promotion of the SCO process.

The security concerns on the domestic, regional and extra-regional levels are highly cross-linked, and the interface of these connections is particularly important for understanding regional security practices. As Sajjadpour (1994, 197) puts it, "the greatest threats to Central Asian security are seen to be more internal $\cdots$ the painstaking process of nation building, the legitimacy crisis, rapid social 
and economic transformation, decolonization, ethnic diversity, border disputes, and a catalogue of other issues are all sources of instability in the post-Soviet republics." Furthermore, Smith $(1996,7)$ indicates the importance of regional competition for dominance, pointing out that "geographic, political, financial, religious, and ethnic factors affect the ability of each to achieve its security goals and promote its hegemonic aspirations."

This fact is also emphasized in the SCO Charter where member-states, Central Asian republics, China and Russia, chose to reaffirm Westphalian sovereignty concepts in the "mutual respect of sovereignty, independence, territorial integrity of States and the inviolability of state borders, non-aggression, non-interference in internal affairs, non-use of force or threat of its use in international relations and seeking no unilateral military superiority in adjacent areas." In this context, Allison $(2008,186)$ points out that for the Central Asian leaders, sovereignty "is not merely a feature of the search for national identity. It also characterizes their approach to political power more generally, which helps explain their disinclination to cooperate deeply on a regional basis, except as a form of mutual reinforcement of the political status quo."

The SCO allows governments to increase their sovereignty through provisions of safety and identity for the people while they strive to establish their own legitimacy. In this context, "sovereignty" in its application to Central Asia must be seen as an integral part of security. According to Menon and Spruyt (1999, 91) security in the context of sovereignty in Central Asia must be seen as a "legitimacy tool," while "local governments face three principal domestic challenges: creating a national identity, building effective political institutions, and coping with late economic development." Hence, regional integration is herein perceived as a process. It is not fixed, but is constantly being transformed by the member states. This contrasts dramatically with the fixed structural rigidity of realism and the institutional functionality of liberal institutionalism. But even this falls short of covering the complexity of identities. The next section examines and describes the model of security identity change.

\section{THE MODEL OF IDENTITY CHANGE THROUGH ACCULTURATION}

The social aspect of cooperation in international organizations is generally described as socialization. The importance of socialization is presented based on the premises offered by the psychologist Katz $(1959,32)$ with regards to the functionalist notion of cognition: that individuals respond to sensory feedback from their operating environment. Although Katz feels that this process may not be so applicable to the more abstract decision-making at the national or international level, involvement in international organizations leading to social- 
ization makes it increasingly relevant. Socialization is a process of inducting actors into the norms and rules of a given community, with compliance based on the internalization of these new norms. "In adopting community rules, socialization implies that an agent switches from following the logic of consequences to a logic of appropriateness; this adoption is sustained over time and is quite independent from a particular structure of material incentives or sanctions" (Checkel 2005, 804).

Goodman and Jinks (2004, 621-703) identify three different mechanisms of influence on states: coercion, persuasion and acculturation. In the case of the SCO, the process of acculturation between individuals and groups representing states has the strongest influence. Acculturation is the exchange of cultural features that results when groups of individuals having different cultures come into continuous firsthand contact (Kottak 2005, 209). The basis of such a claim is in the nature of these processes. The processes of coercion and persuasion are differentiated from the process of acculturation by the mechanisms of regionalization. The first two are calculated and weighed actions taken by a state in response to the external environment, whereas the process of acculturation takes place in a different, internal organizational setting.

The main political method for making decisions on certain issues in the SCO is a consensus-seeking mechanism. Members are shielded from the immediate coercion and persuasion of other members, larger or smaller, by the power of anonymous voting. Moreover, "properly considered, persuasion-like coercion-can and does occur outside international organizations" (Goodman and Jinks 2004, 665). Therefore, it is possible to conclude that acculturation is the primary process of socialization in the SCO that influences the members. The effects of acculturation are complex, as they influence the two other processes, persuasion and coercion. Adhering to Ko's $(2005,977)$ trichotomy of socialization, acculturation is a core process that takes place in organization. As reflected in Figure 1 below, it is a binding one.

\section{Figure 1. Trichotomy of Socialization Processes}

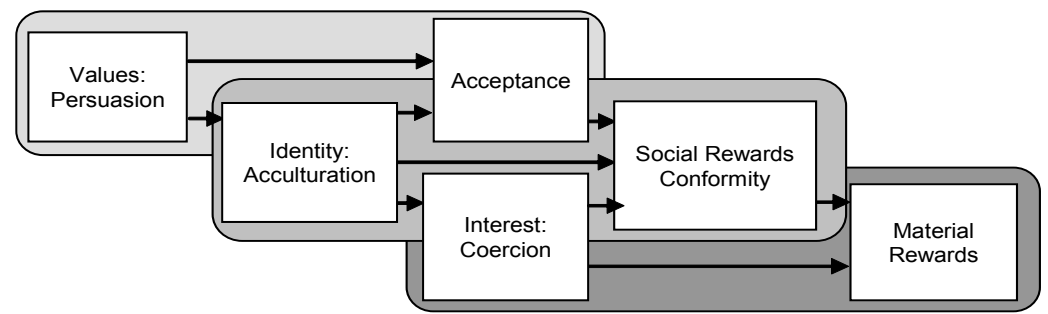

NOTE: Based on Jepperson et al. 1996: 53.

At this stage it is necessary to take a closer look at acculturation. For Pernille Rieker (2010, 9), the nation-state security identity can be identified by uncovering 
the dominant security discourse undertaken by the political leadership in a given nation-state. In order to detect the identity change, we need to identify the phases of acculturation. Rieker's five-phase model of socialization has major shortcomings as it mixes the three, essentially different, processes. The complex five-phase model leaves out the possibility of a high deviation in change, which is problematic if one tries to pinpoint at what stage the change of identity has actually happened, as the differences between the phases are somewhat blurred. The simplification of the above model makes the task easier. That is, if we are able to demonstrate that acculturation has taken place, then the change of identity is present.

Acculturation may have a much deeper and long-term influence, even though on the surface persuasion and coercion may look more effective (Goodman and Jinks 2004, 699). Therefore, the goal is to focus on acculturation as evidence of a security identity change, as shown in Figure 2.

\section{Figure 2. Acculturation as Identity Change}

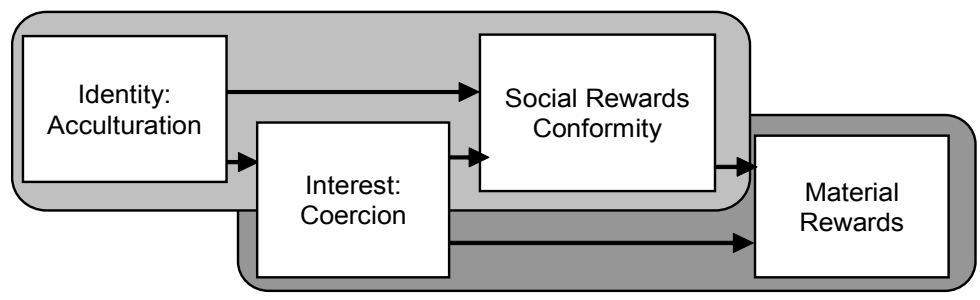

Despite its shortcomings, Rieker's model must be credited for an attempt to chart the process of socialization. The proposed model (above) is certainly far from perfect, but it distinguishes between the aspects that Riecker's model does not. For example, it can be argued that phase 1, which Rieker (2010, 59) describes as "traditional security concerns prevail," actually is a condition, not a phase. The traditional security concerns are based on a set of values that the state initially tries to preserve. These values are primarily built on the locally-constructed concept of sovereignty. Haugevik (2010) advances the idea of socialization, but fails to achieve a clear distinction between strategic adaptation and security identity change. The guiding rule of distinction is when a behavior of the state becomes a norm. If a state is following certain rules without external influence and is not motivated by any interest, then the norm becomes internalized.

According to Goodman and Jinks (2004, 643), "acculturation depends less on the properties of the rule than on the properties of the relationship of the actor to the community. Because the acculturation process does not involve actually agreeing with the merits of a group's position, it may result in outward conformity with a social convention without private acceptance or corresponding changes in private practices." Here, with the assumptions and the critique mentioned above, this paper proposes a revised model of socialization, with acculturation 
as a central mechanism. In the following four case studies, this model will be applied to assess the change in national security identities.

\section{Phase I: Ideas Introduced}

The first phase of socialization through acculturation begins when the norm is introduced in a public venue within the SCO (such as summit, group communiqué, or conference). It begins to be publicly discussed and, as the new security rhetoric takes shape, members begin to absorb the information and evaluate it.

The transmission of information and the inculcation of social values and norms between the members within the SCO begin as new ideas are introduced.

\section{Phase II: Evaluation}

In the second phase, actors begin to think in ways consistent with the social roles and expectations internalized by such norms. Once the actors internalize some role (or any other identity formation), they are impelled to act and think in ways consistent with the highly legitimated purposes and attributes of that role (Goodman and Jinks 2004, 643).

Identity evaluation and identification of interests in proposed securitization such as security regionalization is achieved through the socialization.

\section{Phase III: The Role adoption}

Actors hoard social legitimacy and social status, and they minimize social disapproval. A cognitively accepted role is expressed in actions, mimicry, language patterns, and lexicon use. Members begin to accept the norms and utilize them domestically.

The adoption of a particular convention is expressed in role-guided behavior when the Central Asian states communicate with each other concerning regional issues.

\section{Phase IV: Conformity}

The member states internalize the norm. It becomes independent from external influence, as the norm is taken as a valued national interest. By this stage the national security identity change has been accomplished.

Conformity with the norm and internalization is achieved.

It is also important to mention that the process of acculturation is not linear, and it is proper to focus on its end results or effects. "The acculturation approach suggests that restrictive membership might foster greater affinity among insiders-thus accelerating processes of norm diffusion within a group. The social 
meaning of exclusivity-created by the restriction itself-should intensify forms of identification" (Goodman and Jinks 2004, 671). Therefore, the effects of acculturation will suggest a likelihood of homogenization between the security discourses across the region and contrast with one that is extra-regional. National security preferences can therefore indicate a change or modification beyond simple influence from external or internal factors.

Actors are amenable to social influence via the acculturation processes. These processes-including orthodoxy, mimicry, and status maximization-mobilize internal and external pressures impelling actors, under the right conditions, to adopt socially legitimated attitudes, beliefs, and behaviors (Goodman and Jinks 2004, 642).

This implies that the national security identity and security interests would have to change. Evidence suggesting modified policies could also be found in strengthened national approaches to regionalization in line with the SCO's prescription. Empirically this evidence reflects two elements: national security discourses mirroring that of the SCO, and regional prioritization in the construction of traditional national security interests and preferences. First, we will address elements of domestic national discourse that emphasize the SCO and SCO-developed concepts. Next we will show how the sovereignty of neighbors is being promoted along with the national interests of a state. Finally, we will look at how regional security is becoming the focus of national security discourses across the Central Asian region.

\section{SECURITY IDENTITY CHANGE IN CENTRAL ASIA}

This paper is based on the constructivist-based approach that frames security as a construct that has a specific meaning only in a particular social context. Therefore, the task of conceptualizing security is bound by the discourse that is applied in a particular region. In other words, studying the ideas about security and their development as a first stage, then their ascension to the sphere of public policy (political debate and domestic bargaining), and finally their eventual institutionalization as an organization (norms, roles and practices) will help us understand the complexity of security in a particular region.

Any security-related conceptualization revolves around the political discourses of the state. Conceptualization is "a relational totality which constitutes and organizes social relations around a particular structure of meanings" (Doty 1996, 239). Analysis of Central Asian regional security formulation in the context of the SCO is made around two main discourses: sovereignty and regional cooperation. It is impossible to look at any security conceptualization in this context without 
having a deeper understanding of the interplay between the two.

The modern state system is built on the organizing principle of sovereignty, which seeks coherence among the concepts of the state, the nation and territoriality. This coherence has yet to be achieved in the Central Asia region since "the adoption of the mantle of nationalism by the Central Asian leadership, a measured tactic to avert a looming crisis of legitimacy, encourages national assertiveness among titular ethnic groups and places an unprecedented strain on inter-ethnic relations" (Akbarzadeh 2004, 691). The strength of sovereignty for Central Asian states also lies in constructing a well-developed and neighbor-friendly, or region-oriented, national security identity. The next four cases will illustrate how the SCO's collective identity shaped the change in the security identities of Kazakhstan, Kyrgyzstan, Tajikistan and Uzbekistan.

\section{Kazakbstan: Regional Accommodator and Peace Guarantor}

Traditional security discourse has always been a composite part of Kazakhstan's security identity. In the period between 1992 and 1997, Kazakhstan established its forces and took a clear position toward the strengthening its national security through international recognition and participating in several security organizations. Since its independence it has stood committed to denuclearization and has striven to become an equal member of the international community. This involved strengthening its sovereignty and territorial integrity. Gradually, however, after Kazakhstan became a member of the SCO in 2001, we can see a change in its security tone. Kazakhstan has actively utilized the SCO framework to promote the organization's influence in the region. Kazakhstan took the position of a mediator and facilitator. That led the main security discourse in Kazakhstan to change accordingly. The SCO became an engine for Kazakhstan to change the perception of itself that it had been creating on the regional and extra-regional levels. At this stage, closer to the end of 2006, the change in its security identity fell in line with the collective identity of the SCO. Kazakhstan was becoming a guarantor of regional security (Interfax 2006).

The evidence suggests that the security identity of Kazakhstan moved beyond phase three of the model of the socialization process. The fact that the national security discourse increasingly used the terminology offered by the SCO confirms that particular influence. An expert from Kazakhstan's main security think tank noted in a personal interview that "Kazakhstan views its membership pragmatically. Kazakhstan's role varies in international organizations. In the SCO, however, Kazakhstan's interests have become broader. They look beyond national borders."1 Moreover, Kazakhstan resented Russia's new "vector" terminology as one that would have put Kazakhstan into an inferior position, had Kazakhstan accepted it. In regional diplomacy "each vector of Russia's foreign policy presupposes the solution of specific tasks" in one or the other region (Lavrov 2006, 70). 
Kazakhstan's 2007 Military Doctrine indicated that the security identity of Kazakhstan had changed in several ways. First, this document distinctly differentiated between the two types of security in which Kazakhstan was situated: traditional and non-traditional. In the sphere of non-traditional security it gave priority to the SCO (Tasbulatov 2008). Indicating a change in the national security approach, the doctrine also marked the beginning of a new orientation in Kazakhstan's security approach, as it charted the move from the territorial toward a military force capable of reacting to new threats to the "vital interests of Kazakhstan" (Ermagambetova 2008). By that time, the legislation was modified in two ways. It enabled Kazakhstan's military to deploy its troops outside its territory. And, it allowed foreign troops to enter or cross Kazakhstan's territory under the auspices of the SCO to order and conduct military drills organized by the SCO. The regional dimension has facilitated Kazakhstan's security approach, which eventually extended even further. As Kazakhstan's image changed and it promoted itself as a guarantor on a regional scale, it began to seek a relationship with NATO under the program "Partnership for Peace" (PfP) (Kuzmin 2009).

Kazakhstan's security discourse has apparently moved into phase four of the model of socialization. This happened after the SCO summit in 2008, when it became clear that President Nazarbayev would play a more crucial role in the upcoming CIS summit. Kazakhstan has become increasingly independent from extra-regional influence in constructing its security discourse. It accepted the role of being a peace guarantor in the region, internalized norms of the $\mathrm{SCO}$, and conformed to them.

The change in the security discourse is also supported by recent events. The tactical anti-terror drills, "Peace Mission-2010," which were held under the framework of the SCO, included military forces from six states (each SCO member committed at least one operational-tactical group, in total, 5,000 soldiers) and were successfully executed on the territory of Kazakhstan. This indicates a level of trust between the members, especially given the fact that Kazakhstan allowed foreign forces (ground and air) to be present on its sovereign territory (Ministry of Defense of PRC 2010). The security discourse in Kazakhstan has moved beyond its national orientation and has strongly aligned itself with the SCO security approach in the context of the Central Asian region.

\section{Kyrgyzstan: A Stranger Amongst Friends}

The dynamics of change in Kyrgyzstan are different, due to the nature of its political regime. Despite initial hopes for democratization, a decade-long period of political instability in Kyrgyzstan has derailed many reforms, both nationally and with regard to regional participation. The current interim government, while trying hard to reconcile the differences and heal wounds, looks to security organizations to help rebuild the nation. A decade of membership 
in the SCO has influenced Kyrgyzstan's security identity rather subtly. This is mostly due to the fact that changes in Kyrgyzstan's security approach are primarily driven by the domestic political situation. Kyrgyzstan's ruling elite, before developing a properly defined national security identity, found it difficult to define national interests. The two volatile regime changes have undermined attempts at building an identity properly articulated to the public and to the region.

The first phase of the modified model of socialization is the introduction of new ideas. Even though the SCO was created some time after the Central Asian states gained independence, the fundamental ideas underpinning the organization were already present in the "Shanghai Five" forum, and thus Kyrgyzstan had already been introduced to these ideas. Due to a lack of national resources, Russia's influence in Kyrgyzstan's traditional security conceptualization is still prevalent. Kyrgyzstan still has to rely on Russia to equip its military. In order to strengthen its political power, Kyrgyz leaders have looked to the Collective Security Treaty Organization (CSTO). Kyrgyzstan has requested help from the Organization several times at critical moments in its history. However, it received little more than moral support from the members.

The fact that Kyrgyzstan is yet to stabilize fully makes it difficult to claim that Kyrgyzstan has a well-defined national security identity. Nevertheless, the Kyrgyz elite have consistently been using major themes borrowed from the SCO to build national security discourses. Membership in the SCO has not just been successful; it has been essential. The regional level of cooperation between Kyrgyzstan and China is defined by the relations through the SCO. The open format of the relationship guarantees Kyrgyzstan that its national interests are counted. The participation of two regional superpowers-Russia and China-in the complex Central Asian operating environment is yet another reason why Kyrgyzstan increased its activity in the SCO in the period from 2004-2007. The hope for fair and equal participation is essential for state projects in the economic, energy and financial spheres. The fight with "the three evils"-terrorism, separatism and extremism-in the SCO satisfies Kyrgyzstan's needs in the sphere of security (Aris 2009, 457). All these create the necessary conditions for Kyrgyzstan to achieve its political stability.

The Vice-President of the Institute of Strategic Analysis and Prognosis, a key think tank advising the President on security issues, has noted that "the norms of the SCO, such as 'equal participation and fair attitude', must be the key tasks in Kyrgyzstan's foreign policy in the Central Asian region, and between all the SCO members," and that relations of "good neighborliness" go beyond a simple declarative annunciation, with, in reality, relations in the region being built on them (Usubaliev 2009). The elite in Kyrgyzstan are receptive to the ideas proposed in the SCO. The Kyrgyz national security discourse, though not fully defined, in its themes often echoes those that are raised in the SCO. 
Moreover, on every possible occasion the government projects itself through the SCO's collective identity. It may be too early to speak of an identity change under the influence of the SCO. But here we at least are able to see that Kyrgyzstan has taken on board some policies proposed at SCO forums.

\section{Tajikistan: Life-Beaten Actor}

Tajikistan differs from the other Central Asian states largely due to its painful civil war between 1992 and 1997. This period is characterized by a critical political search by the Tajik central government for resolution to its internal conflict, which was eventually achieved with the help of Russia and Uzbekistan. At the same time, this conflict represents the first approach to creating a regional security identity with the goal of resolving internal conflicts. Through this experience, Tajikistan created its national security identity during a period of war. Later on, after joining the SCO, Tajikistan has shown further tendencies towards the adoption of the SCO's security agenda in its national security approach.

Tajikistan's ethnic composition further distinguishes it from other Central Asian states. The majority of the people are Tajiks: Persian-speaking people of Iranian origin. Also, Tajikistan is the only country in Central Asia that has allowed an Islamist party, The Islamic Renaissance Party of Tajikistan, to participate in the political system. Tajikistan, in the search for its national security identity, arrived at a unique hybrid of semi-ideology and semi-nationalism, as Marat (2008) notes: "Tajikistan's production of ideology based on historical narrative became a highly strategic issue after the end of the civil war in 1997." The Tulip revolution in Kyrgyzstan in 2005 did have some effect on the political life in Tajikistan, but it didn't promote democracy. Civil society had deeper roots than it did in Turkmenistan or Uzbekistan, but the heavy price paid during civil war has kept the population away from politics.

Tajikistan's traditional security approach has always been strongly influenced by Russia. The Russian $201^{\text {st }}$ Motorized Rifle Division remains in the heart of the capital and has been a political card in the hands of the Tajik government since Soviet times. However, it always sought to be a free-rider in security relations, looking for security guarantees from Moscow without burden-sharing. Tajikistan has also used the drugs card for its benefit, seeking financial support from the West and others in an attempt to prevent drug trafficking through the country. The security discourse hasn't just moved from domestic issues to the regional level; it has grown to the extra-regional (Nezavisimaya Gazeta 2004).

Social and economic dimensions have moved towards the center of the national security discourse (Xinhua 2006). Attaching these issues to the discourse in the SCO, Tajikistan's hope was to securitize them domestically while achieving recognition for the shift from the members. This low-profile approach has worked 
well for Tajikistan; which has seen a more successful handling of its defense issues than Uzbekistan and Kyrgyzstan. This implies that the security identity of Tajikistan has moved towards the SCO's collective identity. The key emphasis has been put on a comprehensive domestic security approach paralleling that of the SCO.

Despite a large Russian military presence, the central part of the security discourse is linked to the SCO, and considered in the context of socialization and eventual regionalization. Rather than an overt Russian influence, the tendency seems to be towards increased Tajik free-riding under the auspices of the SCO. This interpretation is supported by Tajikistan's further alienation of the Russian-speaking population living in Tajikistan and a brusque attitude towards Moscow.

Linguistic and ethnic (non-Turkic) differences with the other Central Asian states are increasingly being subsumed by the tone and terminology of the security discourse offered by the SCO: "the three evils," sovereignty, and a peaceful coexistence with its neighboring states. Tajikistan is most likely to further its own security through linking and strengthening its statehood and the development of the country. Considering its relations with the superpowers and other countries in the region, Tajikistan supported an "open doors" policy, that sees its role in creating an international environment conducive to the development and stability of national progress. Tajikistan realizes that the development of stable bilateral relations with other countries is likely to take considerable time and effort. New initiatives are required to deal with increased superpower competition, to strengthen its influence, and to safeguard and promote its national interest (Rakhmon 2010). This is where the SCO is seen as an indispensable tool of Tajikistan's foreign policy.

\section{Uzbekistan: Geopolitical "Poker" Player}

Compared to that of Kazakhstan and Tajikistan, Uzbekistan's regional security orientation is one of geopolitical maneuvering. Its national security identity has changed radically at least twice. The first turn was when, with the goal of limiting Russia's influence in Central Asia, Uzbekistan joined the West-oriented Georgia, Ukraine, Uzbekistan, Azerbaijan, and Moldova group (GUUAM) in 1999. Later, in the sudden realization of its self-isolation and polarization against the whole region, Uzbekistan made its second turn: it decided to withdraw from GUUAM and join the SCO. Uzbekistan's security identity can be characterized as a polarizing identity; one that tries to contradict the others. The three periods in Uzbekistan's security identity are linked to national and regional developments.

As a result of the bloody Andizhan events of May 13, 2005, when government troops indiscriminately killed men, women, and children, the Uzbekistan government came under strong pressure from the West (Hill and Jones 2006, 111). 
The previous 10 years of productive relations between Uzbekistan and the United States were suspended. Within six months, the U.S. military forces had been expelled and all its bases in the territory of Uzbekistan closed (Independent News Service Uzbekistan 2009). Consequently, Uzbekistan lost significant international capital and has been criticized by the West ever since.

In 1998 Uzbekistan stopped and later, in 2006, restored its membership in the CSTO. Uzbekistan's membership in the CSTO is still a "power struggle" with Russia and other members. The SCO is different. Uzbekistan's membership not only expands the sphere of the SCO's activity, but actually provides effective solutions to existing regional problems. For example, at the SCO summit, Russia's President Putin praised Uzbekistan's participation in the Five as "special" (Egorov 2000). The SCO members view terrorism as an international threat and call it "a global threat." In the past decade it has become a major theme in the security discourse of Uzbekistan. The strength of Uzbekistan's security identity lies in the guarantees that are laid out by the principles and norms of the SCO. For example, in the Andizhan crisis the President of Uzbekistan, Islam Karimov, invoked an adherence to the principle of national sovereignty and non-interference to counter accusations from the United States. Moreover, its SCO membership has helped Uzbekistan to strengthen its sovereignty and the right to non-interference, although it also puts some limits on its actions toward its neighbors.

Yet its neighbors perceive Uzbekistan as the most aggressive state in the region (ICG 2002). Uzbekistan is seen not only as a threat in territorial disputes, but also in ideological ones. Uzbekistan turned itself into an Islamic state, but that led to an immediate internal conflict with the democratic parties and the non-Uzbek population, which in turn forced the government to take more authoritarian measures in order to maintain internal control and stability. These moves have earned criticism from its neighbors, as those opposing forces have sought support from similar-minded people across Uzbekistan's borders.

Uzbekistan's security within the SCO has always been to seek comparative benefits against its neighbors. Uzbekistan continues to promote its national interests, but its voice is now heard with reference to the whole region and in the context of regional security, a clear shift in discourse. Also, despite its polarizing nature, Uzbekistan's security approach converged with that of the SCO towards the end of the first decade of the twenty-first century. Indeed, there are close parallels between the priorities of the Uzbek leadership and the SCO's mission:

The scale of narco-aggression, international terrorism, extremism and other threats is increasing. The scale of narco-agression, international terrorism, extremism, and other threats is constantly expanding. All these demand that we strengthen the alertness of our defense forces by maximizing and strengthening our national borders (Eurasianet 2010). 
The security identity change also can be confirmed in the words of President Karimov, who said recently, "Each country (members of the SCO) has its interests, and these interests dictate that they remain as members of the SCO. If the SCO didn't exist, then it should have been created" (RIA News Agency 2007).

Thus, we may see a significant change in Uzbekistan's security discourse. In Karimov's words, Uzbekistan's security approach to a large extent requires the SCO's framework. Moreover, it also indicates that the security issues raised in the SCO and integrated in the national security and defense policy allow us to conclude that the security identity has been transformed. Through its years of membership, Uzbekistan's behavior in the SCO and beyond has become more temperate. Moreover, the organization itself, in the words of President Karimov, is a vital necessity for Uzbekistan and the region.

\section{CONCLUSION}

The identity of any state in Central Asia is tied in at least two aspects to the identity of Central Asia: first, they share similar characteristics with other states in the region, and second, they are connected with the identities of the other states in one way or another. The same logic can be traced in the conceptualizing security identity of the Central Asian states. That is, when we speak of the security identity of Kazakhstan, for example, it must be understood in the context of the region.

The SCO is unique in representing a symbiosis of two approaches to regional governance (Rozoff 2009). On the one hand, there is a multilateral approach among SCO members largely induced by China's leadership and influenced by the Westphalian norms, particularly with regard to national sovereignty and territoriality (Chung 2004, 993). Yet, while the SCO is based on the principles of non-interference, it tries to promote soft-regionalism and cooperative security (Lanteigne 2005). These features of the SCO have allowed the Central Asian states to avoid excessive "edginess" in conflict situations. The events that might have led to an escalation of tensions between the states, once they became public, were subsumed by the norms reiterated in the SCO charter. Extensive efforts in the development of dialogue and consultations have been made within the SCO as it has expanded its normative institutional structure. It is still too early to speak of full-scale regional integration, but the SCO's regional security influence is a fact. Moreover, the influence of the SCO goes beyond the region, as members of the organization promote the fundamental concepts of the SCO in other international organizations, such as the UN. Recently, in 2011, a White Paper by the Human Rights in China Organization stated:

[A] recent opportunity that has emerged for the SCO to influence the 
UN Global Counter-Terrorism Strategy is an initiative sponsored by the European Commission (EC) and Norway to "establish" a Central Asian regional counter-terrorism plan-an effort that seems to neglect the fact that such a "plan" already exists in the form of the well-developed and problematic SCO framework. (HRIC White Paper 2011, 120)

In the light of the evidence presented, it seems that the SCO has influenced the Central Asian States in a number of common ways. First, the changes in identities, while not always obvious, do follow the steps of the modified model of acculturation. The Central Asian states are receptive to the ideas and vocabulary offered in the SCO. The convergence of cognition processes among the leaders of all the Central Asian states are very much reflected in the growing similarities between the national military doctrines and security approaches. They learn, evaluate, and absorb the information that is introduced in public venues within the SCO. Publicly discussed ideas in the SCO are transformed into a new security rhetoric shaped by the members on the domestic level.

All four Central Asian states have successfully passed phases one, two and three of the model, with only Kazakhstan and Uzbekistan reaching the fourth phase of acculturation. Kazakhstan's regional approach in security has earned it the reputation of being a regional "peace maker." References by and the actions of government leaders indicate that SCO values have been internalized by Kazakhstan. This seems to be due to the process initiated by the security regionalization in the SCO. The change in security identity of Uzbekistan is even more striking. Even if Uzbekistan's membership in the SCO is seen as a pragmatic decision by the government, the main security orientation of Uzbekistan is instrumental in its national security, and has become more regionalized under the SCO's influence.

Despite difficulties in its economic and infrastructure development, Tajikistan relies greatly upon the SCO, primarily because it is the only multilateral mechanism that holds any promise for, and opens doors to, much needed foreign investments for its national transport and energy projects. In addition, as a result of the promotion of the norms of "good neighborliness," Tajikistan signed the Ottawa convention banning Anti-Personnel Mines (officially known as the Convention on the Prohibition of the Use, Stockpiling, Production and Transfer of Anti-Personnel Mines and on their Destruction) in 1999, and is working on demining its borders. This may indicate that it is growing into the fourth phase. Kyrgyzstan, the country that has been the most unstable and was in crisis in the summer of 2010, is very difficult to predict. Yet, the security approach taken by the military of Kyrgyzstan is in line with the SCO's security approach and in its external dimension it primarily relies on it.

Social values and norms generated by interaction between the member states within the SCO have become the norms guiding, and essential to, regional 
security. Their consistent behavior in accepting such social roles, and the expectations internalized by such norms, strengthen the stability of the region. The identities of the four Central Asian states have in part been formed through this regional dimension, and the SCO impels its members to act and think in ways consistent with the purposes of the organization. Their national interests are securitized in the SCO security construct. The actions, mimicry, language patterns, and lexicon have been internalized by most member states and are being utilized domestically. The concepts or themes introduced in the SCO are guiding their behavior when the Central Asian states interact on regional issues. As the process of acculturation is not linear, the end results or effects are primarily detected in group-thinking by the SCO members. This in effect leads to a homogenization of security discourses across the region and is in contrast to those that are extra-regional.

The overall conclusion is that the SCO plays an important role in the security of the Central Asian region and influences its four members-Kazakhstan, Kyrgyzstan, Tajikistan and Uzbekistan. Inter-subjective understandings between the members influence the security discourse and the dynamics of the organization. It is not exclusively the creature of the super powers which initiated it, but rather it allows the four Central Asian Republics to resolve their internal insecurity and regional security identity dynamics. It is a unique organization at once formal and informal, intergovernmental and collective, practical and imagined. It promotes the Westphalian concepts of political sovereignty and territorial integrity, yet has already had a considerable transformative impact upon the internal governance and imaging of its members, and will likely impact them still more in the future.

\section{REFERENCES}

Akbarzadeh, Shahram. 2004. Keeping Central Asia Stable. Third World Quarterly 25(4): 689-705.

Alderson, Kai. 2001. Making Sense of State Socialization. Review of International Studies 27: 415-33.

Allison, Roy. 2004. Regionalism, Regional Structures and Security Management in Central Asia.International Affairs 80(3): 463-83.

Allison, Roy. 2004. Regionalism and the Changing International Order in Central Eurasia. International Affairs 80(3): 423-27.

Allison, Roy. 2008. Virtual regionalism, regional structures and regime security in Central Asia. Central Asian Survey 27(2): 185-202.

Ambrosio, Thomas. 2008. Catching the 'Shanghai Spirit': How the Shanghai Cooperation Organization Promotes Authoritarian Norms in Central Asia. EuropeAsia Studies 60: 1321-44. 
Aris, Stephen. 2009. The Shanghai Cooperation Organisation: 'Tackling the Three Evils.' A Regional Response to Non-traditional Security Challenges or an Anti-Western Bloc?Europe-Asia Studies 61(3): 457-82.

Aris, Stephen. 2009. A new model of Asian regionalism: Does the Shanghai Cooperation Organisation have more potential than ASEAN?Cambridge Review of International Affairs 22(3): 451-67.

Bhatty, Roj Sultan Khan. 2008. Russia: The Traditional Hegemon. In Central Asia.Perceptions. Ministry of Foreign Affairs, Istanbul.Accessed March 3, 2010. http://sam.gov.tr/wp-content/uploads/2012/01/Roj-Sultan.pdf.

Blank, Stephen. 2007. U. S. Interest in Central Asia and Their Challenges. Demokratizatsiya.

Bohr, Annette. 2004. Regionalism in Central Asia: New Geopolitics, Old Regional Order. International Affairs 80(3): 485-502.

Brooks, Stephen G., and William C. Wohlforth. 2005. Hard Times for Soft Balancing. International Security 30(1): 72-108.

Bull, Hedley, and Adam Watson. 1984. Introduction. In The Expansion of International Society, eds. Hedley Bull and Adam Watson. Oxford: Oxford University Press.

Bull, Hedley. 1977. The Anarchical Society. A Study of Order in World Politics. London: Macmillan.

Buzan, Barry, Ole Waever, and Jaap de Wilde. 1997. Security: A New Framework For Analysis. London: Boulder.

Buzan, Barry. 2000. The Logic of Regional Security in the Post-Cold War World. In The New Regionalism and the Future of Security and Development 4, eds. Bjorn Hettne, Andras Inotai, and Osvaldo Sunkel. London: Macmillan.

Carney, Christopher P., and John P. Moran. 2000. Imagining Communities in Central Asia: Nationalism and Interstate Affect in the Post-Soviet Era.Asian Affairs 26(4): 179-98.

Checkel, Jeffrey T. 2005. International Institutions and Socialization in Europe: Introduction and Framework International Organization. International Institutions and Socializationin Europe 59(4): 801-26.

Chung, Chien-peng. 2004. The Shanghai Co-operation Organization: China's Changing Influence in Central Asia. The China Quarterly 180: 989-1009.

Chung, Chien-peng. 2006. China and the Institutionalization of the SCO. Problems of Post-Communism 53(5): 3-14.

Collective Security Treaty Organization (in Russian). Accessed December 8, 2009. http://odkb.gov.ru/start/index.htm.

Cornell, Svante E. 2003. Regional Politics in Central Asia: the Changing Roles of Iran, Turkey, Pakistan and China. In India and Central Asia: Building Linkages in an Age of Turbulence. New Delhi: SAPRA Foundation.

Dawson, R., and K. Prewitt. 1969. Political Socialization. Boston: Little, Brown.

Doty, Roxanne Lynn. 1996. Immigration and National Identity: Constructing the Nation. Review of International Studies 22(3): 235-55. 
Egorov, Yuri. 2000. Europe is concerned of threats arising from Central Asia: The president of Uzbekistan chose the summit in Dushanbe instead of meeting with the Secretary-General of NATO. Nezavisimaya Gazeta, August 7. http:// www.ng.ru/cis/2000-07-07/5_europe.html.

Ermagambetova, Dina. 2008. Kazakh President on the eve of the Day of Defender visited a military unit. Astana KazInform Agency, May 6. Accessed October 27, 2011. http://www.enbek.gov.kz/node/236716.

Eurasianet Report. 2010. The Speech of the President of Uzbekistan on the National TV. January 13. Accessed April 10, 2011. http://russian.eurasianet. org/node/30933.

Goodman, Ryan, and Derek Jinks. 2004. How to Influence States: Socialization and International Human Rights Law. Duke Law Journal 54(3): 621-703.

GUUAM Organization. Accessed January 26, 2011.http://www.guuam.org/general/browse.html.

Haugevik, Kristin Marie. 2006. Strategic Adaptation or Identity Change? An Analysis of Britain's Approach to the ESDP 1998-2004. Oslo, Norway: NUPI.

Hill, Fiona, and Kevin Jones. 2006. Fear of democracy or revolution: The reaction to Andijon. The Washington Quarterly 29(3): 111-25.

Hooghe, L., and G. Marks. 2001. Multi-Level Governance and European Integration. Lanham, Maryland: Rowman and Littlefield.

Independent News Service Uzbekistan. 2009. How in 2005 Karimov kicked out Americans. February 10. Accessed October 16, 2011. http://www.uznews.net/ news_single.php?lng $=$ gvnhrpsj\&sub $=$ \&cid $=31$ \&nid $=8713$.

Human Rights in China Organization. 2011. Counter-Terrorism and Human Rights: The Impact of the Shanghai Cooperation Organization. Whitepaper. Hong Kong: HRIC.

Interfax News Agency. 2006. As a head of the OSCE Kazakhstan will be a guarantor of Asian security. June 13. Accessed October 6, 2011. http://www. lenta.ru/news/2006/06/13/nazarbaev/.

International Crisis Group. 2002. 'Central Asia: Border Disputes and Conflict Potential.' ICG Asia Report 33, April 4. Accessed December 16, 2011. http:// www.crisisgroup.org/ /media/Files/asia/central-asia/Central\%20Asia $\% 20$ Border\%20Disputes\%20and\%20Conflict\%20Potential.pdf.

Jepperson, Ronald L., Alexander Wendt, and Peter J. Katzenstein. 1996. Norms, Identity, and Culture in National Security. In The Culture of National Security, ed. Peter J. Katzenstein. New York: Columbia University Press: 33-75.

Katz, Daniel. 1959. Consistent Reactive Participation of Group Members and the Reduction of Intergroup Conflict. Journal of Conflict Resolution 3(1): 28-40.

Koh, Harold Hongju. 2005. Internalization through Socialization, Thirty-Fourth Annual Administrative Law, Incrementalism and the Administrative State. Duke Law Journal 54(4): 975-82.

Kottak, Conrad Phillip. 2005. Windows on Humanity. New York: McGraw Hill. Kuzmin, Nikolai. 2009. Caspian-Atlantic Union: Kazakhstan rejected drills but 
not the cooperation with NATO. Expert Kazakbstan 19(213).

Lanteigne, Marc. 2005. China and International Institutions: Alternate Patbs to Global Power. London: Routledge.

Lavrov, Sergei. 2006. The Rise of Asia, and the Eastern Vector of Russia's Foreign Policy. Russia In Global Affairs 4(3): 68-80.

Marat, Erica. 2008. National Ideology and State-building in Kyrgyzstan and Tajikistan. Washington, D. C.: Johns Hopkins University-SAIS.

Marketos, Thrassy N. 2009. China's energy Geopolitics: the Shanghai Cooperation Organization and Central Asia. NewYork: Routledge.

Menon, Rajan, and Hendrik Spruyt. 1999. The Limits of Neorealism: Understanding Security in Central Asia Author. Review of International Studies 25(1): 87-105. Menon, Rajan. 1997. In the Shadow of the Bear: Security in Post Soviet Central Asia. International Security 20: 149-81.

Ministry of Defense of PRC. 2010. Peace Mission-2010. SCO Anti-terrorism Joint Exercise. Accessed September 21, 2011. http://eng.mod.gov.cn/Special Reports/SCO Joint Military Exercises.htm.

Mukhin, Vladimir. 2004. NATO-Russia conflict is just beginning: Diplomats behind the military matters defending Russian interests in the post-soviet countries. The Nezavisimaya Gazeta, April 4. Accessed December 26, 2011. http://www.ng.ru/courier/2004-04-05/11_nato.html.

Nanay, Julia. 2007. Inside Track: SCO Gaining Importance. The National Interest Online.

Nourzhanov, Kirill. 2009. Changing security threat perceptions in Central Asia. Australian Journal of International Affairs 63(1): 85-104.

Ong, Russell. 2005. China's security interests in Central Asia. Central Asian Survey 24(4): 425-39.

Rachmonov, Emomali. 2006. The President of Tajikistan to the Chinese media in Dushanbe. The President of Tajikistan speaks about important role of the SCO. Xinhua Agency, June 10. Accessed September 20, 2011. http://russian.china.org.cn/russian/242521.htm.

Rashid, Ahmed. 2000. The New Struggle in Central Asia: A Primer for the Baffled. World Policy Journal 17(4): 33-45.

RIA News Agency. 2007. Karimov: If the SCO didn't exist, then it should have been created. July 5. Accessed April 25, 2011. http://www.rian.ru/politics/20050705/40845768.html.

Rieker, Pernille. 2010. Europeanization of National Security Identity. London: Routledge. Rozoff, Rick. 2009. The Shanghai Cooperation Organization: Prospects for a Multipolar World. Global Research. May 22. http://rickrozoff.wordpress.com/ 2009/08/29/150/.

Sajjadpour, Seyed Kazem. 1994. Iran, the Caucasus and Central Asia. In The New Geopolitics of Central Asia, eds. Ali Vanauzizia and Myron Weiner. Bloomington: Indiana University Press. 
Shambaugh, David. 2004. China Engages Asia: Reshaping the Regional Order. International Security 29(3): 64-99.

Shanghai Cooperation Organization. 2009. Joint Communiqué of Meeting of the Council of the Heads of the Member States of the Shanghai Cooperation Organization. June 16. Accessed December 1. http://www.sectsco.org/EN/show.asp?id $=88$.

Shanghai Cooperation Organization. Accessed December 1, 2009. http://www. sectsco.org/EN/brief.asp.

Sheives, Kevin. 2006. China Turns West: Beijing's Contemporary Strategy Towards Central Asia. Pacific Affairs 79(2): 205-24.

Smith, Dianne L. 1996. Central Asia: A New Great Game? Asian Affairs 23(3): 147-75.

Tajin, Marat. 2000. National Security of Kazakhstan: New Understanding, New Approaches. 'Analitika' Analytical Center Prudent Solutions. Accessed May 12, 2011.http://analitika.org/2077-20051121055326518.html.

Tasbulatov, Abai. 2008. Nursultan Nazarbaev-the Guarantor of Military Security of Our Country. The Kazakhstanskaya Pravda Daily Newspaper, June 29. Accessed April 20, 2011. http://www.kazpravda.kz/c/1214602782.

U. S. Congress. 2006. 109 ${ }^{\text {th }}$ Congress Hearing: 'The Shanghai Cooperation Organization: Is it Undermining US Interests in Central Asia?' United States Commission on Security and Cooperation in Europe (Helsinki Commission).

Usubaliev, Ednan. 2009. 'China factor' in foreign policy of Kyrgyzstan is dual-bilateral and regional levels. The Central Asia Informational Portal, March 9. Accessed December 06, 2011. http://www.centrasia.ru/newsA.php?st = 12365 99880.

Weller, R. Charles. 2006. Rethinking Kazakh and Central Asian Nationhood. A Challenge to Prevailing Western Views. Los Angeles, CA: Asia Research Associates.

Wendt, Alexander. 1992. Anarchy is What States Make of It: The Social Construction of Power Politics. International Organisation 46(2): 391-425.

Wendt, Alexander. 1994. Collective Identity Formation and the International State. American Political Science Review 88(2): 384-96.

Wendt, Alexander. 1995. Constructing International Politics. International Security 20(1): 71-81.

Wendt, Alexander. 1996. Identity and Structural Change in International Politics. In The Return of Culture and Identity in IR Theory, eds. Y. Lapid and F. Kratochwil. Boulder, CO: Lynne Rienner Publishers.

Wendt, Alexander. 1999. Social Theory of International Politics. Cambridge: Cambridge University Press.

\section{ENDNOTES}

${ }^{1}$ Bulat Auelbayev. 2010. The Head of the Department of Kazakhstan Institute of Strategic Studies under the President of the Republic of Kazakhstan, personal communication. 